\title{
Outcomes after oesophageal perforation: a retrospective cohort study of patients with different aetiologies
}

\author{
TT Law, Jonathan YL Chan, Desmond KK Chan, Daniel Tong, lan YH Wong, Fion SY Chan, Simon Law *
}

\section{A B S T R A C T}

Introduction: The mortality rate after oesophageal perforation is high despite advances in operative and non-operative techniques. In this study, we sought to identify risk factors for hospital mortality after oesophageal perforation treatment.

Methods: We retrospectively examined patients treated for oesophageal perforation in a university teaching hospital in Hong Kong between January 1997 and December 2013. Their demographic and clinical characteristics, aetiology, management strategies, and outcomes were recorded and analysed.

Results: We identified a cohort of 43 patients treated for perforation of the oesophagus ( 28 men; median age, 66 years; age range, 30-98 years). Perforation was spontaneous in $22(51.2 \%)$ patients (15 with Boerhaave's syndrome and seven with malignant perforation), iatrogenic in 15 (34.9\%), and provoked by foreign body ingestion in six (14.0\%). Of the patients, 14 (32.6\%) had pre-existing oesophageal disease. Perforation occurred in the intrathoracic oesophagus in 30 (69.8\%) patients. Emergent surgery was undertaken in 23 patients: 16 underwent primary repair, six surgical drainage or exclusion, and one oesophagectomy. Twenty patients were managed non-operatively, 13 of whom underwent stenting. Two stented patients subsequently required oesophagectomy. Four patients had clinical

This article was published on $10 \mathrm{Mar}$ 2017 at www.hkmj.org. signs of leak after primary repair: two were treated conservatively and two required oesophagectomy.

Overall, six (14.0\%) patients required oesophagectomy, one of whom died. Nine other patients also died in hospital; the hospital mortality rate was $23.3 \%$. Pre-existing pulmonary and hepatic disease, and perforation associated with malignancy were significantly associated with hospital mortality $(\mathrm{P}=0.03,<0.01$, and $<0.01$, respectively).

Conclusions: Most oesophageal perforations were spontaneous. Mortality was substantial despite modern therapies. Presence of pre-existing pulmonary disease, hepatic disease, and perforation associated with malignancy were significantly associated with hospital mortality. Salvage oesophagectomy was successful in selected patients.

\section{Hong Kong Med J 2017;23:231-8}

DOI: $10.12809 / \mathrm{hkmj} 164942$

TT LaW, FRCSEd, FHKAM (Surgery)

JYL Chan, MB, BS

DKK Chan, FRCSEd, FHKAM (Surgery)

D Tong, MS, PhD

IYH Wong, FRCSEd, FHKAM (Surgery)

FSY Chan, FRCSEd, FHKAM (Surgery)

S Law *, MS, FRCSEd

Division of Esophageal and Upper Gastrointestinal Surgery, Department of Surgery, The University of Hong Kong, Queen Mary Hospital, Pokfulam, Hong Kong

* Corresponding author: slaw@hku.hk

New knowledge added by this study

- We report the outcomes of a cohort of patients with oesophageal perforation managed in a single centre.

- Mortality rate was substantial despite advances in surgery and endoscopic therapy.

Implications for clinical practice or policy

- Surgical and non-operative treatment options are available.

- The aetiology, timing of presentation, and patients' co-morbidities should be considered carefully when managing oesophageal perforation.

- Oesophagectomy may be indicated in selected patients.

\section{Introduction}

Oesophageal perforation is uncommon, yet its management remains a substantial challenge to surgeons. Diagnosis and treatment are often delayed due to lack of clinical suspicion and accurate diagnostic tools. Hence, reported mortality rates range from $10 \%$ to $25 \% .^{1-3}$
Oesophageal perforation can occur spontaneously from forceful vomiting (Boerhaave's syndrome), or in pre-existing pathology (such as oesophageal cancer) or can be associated with ingestion of a foreign body. Iatrogenic perforation usually occurs after therapeutic endoscopic procedures such as dilatation, and is the predominant 


\section{有不同病因的食管穿孔患者的治療結果： 回顧性隊列研究}

\section{羅芷婷、陳應倫、陳君傑、唐琼雄、黃宇匡、陳小燕、羅英傑}

引言：儘管食管穿孔的手術和非手術治療技術不斷進步, 但此病的死 亡率仍然偏高。本研究旨在找出食管穿孔患者醫院死亡率的危險因 素。

方法：回顧分析1997年1月至2013年12月期間在香港一所大學教學 醫院內接受食管穿孔治療的患者。記錄分析病人資料、臨床特徵、病 因、治療策略和結果。

結果：研究期間有43例食管穿孔, 患者年齡介乎30-98歲, 中位數66 歲；其中28名為男性。患者中自發性食管穿孔佔22例（51.2\%）， 包括Boerhaave綜合徵 15 例和惡性穿孔 7 例 ; 醫源性食管穿孔的有 15 例（34.9\%）；食管異物致穿孔的有6例（14.0\%）。患者中有 14 例 (32.6\%) 有食管病病史。胸段食管穿孔的有30例（69.8\%）。有23 例進行急診手術, 包括 16 例修補、6例引流或排除和 1 例食管切除。 接受非手術治療的 20 例中, 有 13 例食管支架置入; 其中 2 例曾接受 支架置入的患者隨後須接受食管切除。4例患者接受食管修補後有臨 床滲漏, 當中2例隨後接受保守治療, 另 2 例接受食管切除。總體而 言, 6例 $(14.0 \%)$ 須進行食管切除, 其中 1 例死亡; 另有9例在醫院 內死亡。醫院死亡率為 $23.3 \%$ 。有肺病病史 $(\mathrm{P}=0.03)$ 、肝病病史 $(\mathrm{P}<0.01)$ ，以及與惡性腫瘤有關的食管穿孔（ $\mathrm{P}<0.01 ）$ 與醫院死亡 率顯著相關。

結論：大多數食管穿孔的病例屬自發性。儘管現代技術不斷進步, 食 管穿孔的死亡率仍然偏高。有肺病和肝病病史, 以及與惡性腫瘤有關 的食管穿孔均與醫院死亡率顯著相關。補救性食管切除在部分患者中 有成效。

\section{Methods}

We retrospectively identified patients treated for perforation of the oesophagus at a university teaching hospital in Hong Kong between January 1997 and December 2013. Patients' demographic characteristics, presentation, investigations, management, and outcomes were recorded.

Diagnosis of perforation was confirmed by one or more of the following methods: oesophagogastroduodenoscopy (OGD), watersoluble contrast swallow study, and contrastenhanced computed tomography imaging of the neck, thorax, and abdomen. After confirmation of the diagnosis, patients were resuscitated to address homoeostatic and haemodynamic disturbances, followed by definitive treatment. All patients were kept 'nil by mouth', administered parenteral broadspectrum antibiotics and proton pump inhibitors, and chest drain(s) was inserted if clinically indicated. Patients with significant haemodynamic instability or respiratory distress requiring intubation and mechanical ventilation were admitted to the intensive care unit (ICU) for optimisation before definitive treatment.

Definitive treatment depended on the location of the perforation, its aetiology, the extent of mediastinal and intrathoracic contamination, and the patient's physical status. In general, patients with malignant perforation or perforation contained within the mediastinal pleura were treated nonoperatively. For the former, self-expanding metallic stents were inserted under fluoroscopic guidance. In selected patients with a benign cause of perforation and limited contamination, a polyester oesophageal stent (Polyflex; Boston Scientific, Natick [MA], United States) was placed under fluoroscopic guidance. For patients in whom the site of perforation could not be identified, and in the absence of clinical signs of sepsis, a conservative management strategy was adopted. This entailed placement of a nasogastric feeding tube under endoscopic guidance, followed by enteral feeding for 7 days. Thereafter, a watersoluble contrast swallow study was undertaken to confirm the absence of a leak before oral feeding was resumed.

When a surgical management strategy was decided, patients with perforation of the intra-abdominal oesophagus were treated with laparotomy, primary repair of the perforation, and feeding jejunostomy. For an intrathoracic perforation with significant contamination of the pleural cavity, thoracotomy and primary repair was the preferred approach. A left-sided thoracotomy was the usual approach for Boerhaave's perforation of the distal thoracic oesophagus. Necrotic tissue was debrided, the edges of the perforation were trimmed, and the defect was closed with fine sutures in two layers. The mucosal edges of the perforation 
were approximated using interrupted absorbable sutures, and the muscular defect was approximated using interrupted monofilament absorbable sutures. Lung decortication was performed. One drain was placed in close proximity to the repair, generally accompanied by one basal and one apical large-bore chest drain. Feeding jejunostomy was performed in selected patients. Postoperatively patients remained nil by mouth, and were given nutritional support and intravenous antibiotics. A contrast swallow study was generally performed 7 to 10 days postoperatively; oral intake was commenced if there was no evidence of leak. The choice of antibiotics and duration of treatment were guided by microbiology culture findings.

In selected patients who presented late, and in those who developed a persistent leak after primary repair, oesophageal exclusion (cervical oesophagostomy and jejunostomy) followed by second-stage oesophagectomy might be considered. In the first stage, the oesophagus was excluded proximally in the neck with an oesophagostomy, and the abdominal oesophagus was stapled. A drain was placed from the neck into the oesophageal stump for decompression. Oesophagectomy was performed once sepsis had subsided. A gastric tube was used for reconstruction via the retrosternal route, and cervical oesophagogastrostomy was performed.

The principles outlined in the Declaration of Helsinki have been followed.

\section{Statistical analysis}

Continuous data were represented as the median (range), unless otherwise stated. Fisher's exact test was used to compare categorical variables and the Mann-Whitney $U$ test for continuous variables. We undertook univariate analysis to identify factors associated with hospital mortality. $\mathrm{P}<0.05$ was considered statistically significant. Data were analysed using SPSS 20.0 (IBM Corp, Armonk [NY], United States).

\section{Results}

During the study period, 43 patients with oesophageal perforation were identified. Patients' demographic and clinical characteristics are summarised in Table 1 . The median age of the cohort was 66 years (range, 30-98 years); 28 (65.1\%) were men. Medical co-morbidities were present in $27(62.8 \%)$ patients, and pre-existing oesophageal pathologies were present in 14 (32.6\%; of whom half had oesophageal cancer). Spontaneous perforation occurred in $22(51.2 \%)$ patients: 15 occurred as a result of Boerhaave's syndrome and seven as a result of malignant perforation. Fifteen (34.9\%) patients had an iatrogenic perforation: 13 occurred after an endoscopic procedure (three after endoscopic retrograde cholangiopancreatography and 10 after
OGD), one occurred after attempted endotracheal intubation, and one occurred during thyroidectomy. Of the 10 OGDs, eight had been therapeutic. Six (14.0\%) perforations were associated with ingestion of a foreign body.

Chest pain and vomiting were the most common presenting symptoms in patients with spontaneous perforation, occurring in 13 and 10 patients, respectively. Surgical emphysema and

TABLE I. Patients' clinical and demographic characteristics

\begin{tabular}{lc}
\hline Characteristic & Data $^{*}$ \\
\hline Sex (M:F) & $28: 15$ \\
Age (years) & $66(30-98)$ \\
\hline Medical co-morbidities & $27(62.8)$ \\
Site of oesophageal perforation & \\
$\quad$ Cervical & $10(23.3)$ \\
$\quad$ Thoracic & $30(69.8)$ \\
\hline Abdominal & $3(7.0)$ \\
Pre-existing oesophageal pathology & $14(32.6)$ \\
\hline Initial treatment & \\
\hline \multicolumn{1}{l}{ Operative } & $23(53.5)$ \\
\hline Non-operative & $20(46.5)$ \\
Intensive care unit stay (days) & $6(0-71)$ \\
\hline Hospital stay (days) & $36.5(6-241)$ \\
\hline Hospital mortality & $10(23.3)$ \\
\hline 30-Day mortality & $7(16.3)$ \\
\hline
\end{tabular}

* Data are shown as No. of patients, No. (\%) of patients, or median (range)

TABLE 2. Presenting symptoms* in patients with spontaneous perforation, and investigations undertaken in all patients

No. of patients with spontaneous perforation $(n=22)$

\begin{tabular}{lc}
\hline Chest pain & 13 \\
\hline Epigastric pain & 6 \\
\hline Dysphagia & 2 \\
\hline Vomiting/haematemesis & 10 \\
\hline Respiratory distress & 6 \\
\hline Surgical emphysema & 2 \\
\hline Time to diagnosis & \\
\multicolumn{1}{c}{$\leq 24$ Hours } & 12 \\
\hline \multicolumn{1}{c}{$>24$ Hours } & 10 \\
\hline Investigations $\dagger$ & $(\mathrm{n}=43)$ \\
\hline \multicolumn{1}{l}{ One modality } & $9(20.9 \%)$ \\
\hline \multicolumn{1}{l}{ Two modalities } & $29(67.4 \%)$ \\
\hline \multicolumn{1}{l}{ Three modalities } & $5(11.6 \%)$ \\
\hline
\end{tabular}

* Patients might have presented with more than one symptom

† Oesophagogastroduodenoscopy, computed tomography, and/or contrast swallow study 
dysphagia were the least common presenting signs and symptoms; both were only present in two patients. Over half the patients presented and were diagnosed within 24 hours of symptom onset. Of the cohort of 43 patients, 29 (67.4\%) underwent two out of the three diagnostic imaging modalities. The presenting symptoms and investigations of patients with spontaneous perforation are shown in Table 2.

The management and outcomes of patients are shown in the Figure. Of the 15 patients with Boerhaave's perforation, 10 underwent primary repair: four repairs were complicated by a leak and two patients subsequently required oesophagectomy. The remaining five patients were initially treated non-operatively: four underwent endoscopic stent placement and one endoscopic clipping of the perforation. Three patients required subsequent operations: one underwent oesophagectomy, one bypass operation, and one surgical drainage.
There were no deaths in the group of patients with Boerhaave's syndrome.

Seven patients had malignant perforation: five were treated with endoscopic placement of a metallic stent. All but one of these procedures were successful; the patient in whom stenting failed underwent oesophagectomy. Five $(71.4 \%)$ of the seven patients with malignant perforation died during their hospital stay.

There were 15 iatrogenic perforations (Fig). Nine of these patients underwent early operative treatment: five underwent primary repair, one exclusion, two drainage, and one oesophagectomy. There were no leaks in those who underwent primary repair. Six patients were initially treated nonoperatively, four with stents, one with a feeding tube, and one was judged to be unfit for treatment. Two of the six patients initially treated non-operatively ultimately required surgery, one underwent

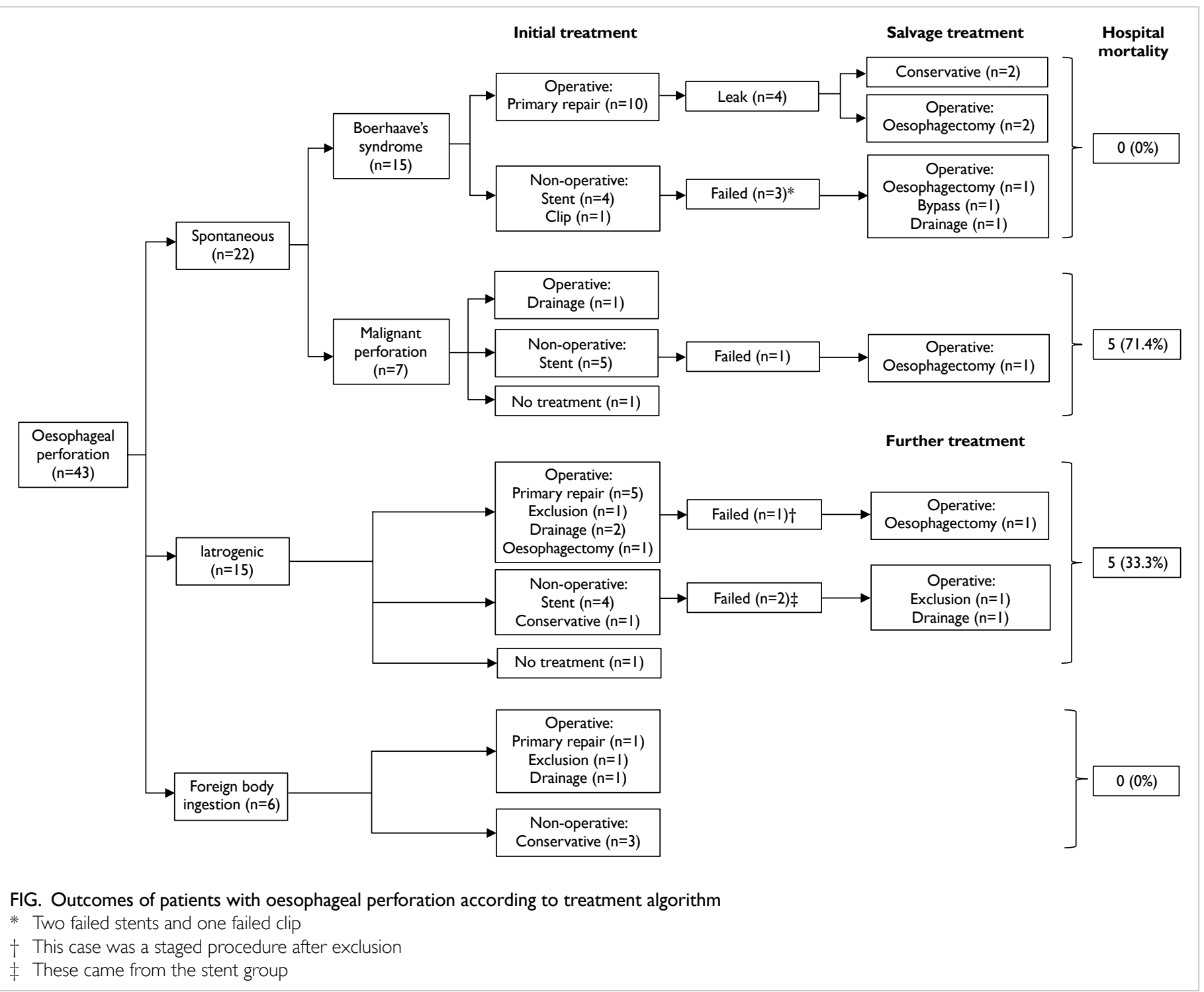


exclusion, and the other surgical drainage. Five of the 15 patients with iatrogenic perforations died during their hospital stay, with a mortality rate of $33.3 \%$.

Six oesophageal perforations were associated with foreign body ingestion (Fig). Three patients were treated non-operatively; of the remainder, one underwent primary repair, one exclusion, and one surgical drainage. None of these patients died during hospitalisation.

Overall, 16 of the 43 patients underwent primary repairs in the initial treatment, and four (25\%) developed clinical signs of leak subsequently. All were from Boerhaave's perforation. Two required oesophagectomy while two were managed conservatively.

Overall, six of the 43 patients underwent oesophagectomy, generally as a salvage treatment due to failure of other treatment modalities. Three patients with Boerhaave's syndrome required oesophagectomy, two with persistent leak after primary repair and one with a persistent leak after stenting. All had presented $>24$ hours from symptom onset. One patient with a perforated oesophageal cancer developed a leak after stenting and required oesophagectomy. Two patients with iatrogenic perforation in the presence of caustic strictures underwent oesophagectomy. Only one patient who underwent oesophagectomy died in hospital.
Overall, 10 patients died in hospital, with a mortality rate of $23.3 \%$. The 30 -day mortality rate was $16.3 \%$. The median length of hospital stay was 36.5 days (range, 6-241 days), and median ICU stay was 6 days (range, 0-71 days).

All 10 patients who died had pre-existing oesophageal disease; five had cancer of the oesophagus, one caustic stricture, and four had oesophageal varices secondary to hepatic cirrhosis. Malignant perforation had a substantially higher mortality rate of $71.4 \%$. The median survival for patients with perforated oesophageal cancer was 28.5 days (range, 13-848 days).

The results of univariate analysis of factors potentially associated with hospital mortality are shown in Table 3 . The presence of pulmonary disease, hepatic disease (liver cirrhosis), and malignant perforation were significantly associated with hospital mortality $(\mathrm{P}=0.03,<0.01$, and $<0.01$, respectively), but the site of perforation and timing of presentation were not.

\section{Discussion}

Oesophageal perforation may be difficult to diagnose. Patients can present with a wide variety of symptoms, which can be non-specific. It is not uncommon for the diagnosis to be missed in the acute phase.

TABLE 3. Univariate analysis of factors associated with hospital mortality

\begin{tabular}{|c|c|c|c|}
\hline Factor & No mortality $(n=33)$ & Mortality $(n=10)$ & $P$ value \\
\hline Median (range) age (years) & $66(30-98)$ & $64(46-81)$ & 0.80 \\
\hline $\operatorname{Sex}(M: F)$ & $20: 13$ & $8: 2$ & 0.24 \\
\hline \multicolumn{4}{|l|}{ Aetiology } \\
\hline Boerhaave's syndrome & $15(45.5 \%)$ & 0 & 0.25 \\
\hline Malignant & $2(6.1 \%)$ & $5(50.0 \%)$ & $<0.01$ \\
\hline latrogenic & $10(30.3 \%)$ & $5(50.0 \%)$ & 0.25 \\
\hline Foreign body & $6(18.2 \%)$ & 0 & 0.25 \\
\hline \multicolumn{4}{|l|}{ Medical co-morbidity } \\
\hline Cardiac & $16(48.5 \%)$ & $5(50.0 \%)$ & 0.81 \\
\hline Pulmonary & $2(6.1 \%)$ & $3(30.0 \%)$ & 0.03 \\
\hline Diabetes mellitus & $4(12.1 \%)$ & $3(30.0 \%)$ & 0.15 \\
\hline Hepatic & 0 & $4(40.0 \%)$ & $<0.01$ \\
\hline \multicolumn{4}{|l|}{ Location } \\
\hline Cervical & $9(27.3 \%)$ & $1(10.0 \%)$ & 0.34 \\
\hline Thoracic & $21(63.6 \%)$ & $9(90.0 \%)$ & 0.34 \\
\hline Abdominal & $3(9.1 \%)$ & 0 & 0.34 \\
\hline \multicolumn{4}{|l|}{ Presentation } \\
\hline Shock & $6(18.2 \%)$ & $4(40.0 \%)$ & 0.14 \\
\hline$>24$ Hours & $9(27.3 \%)$ & $5(50.0 \%)$ & 0.16 \\
\hline Mechanical ventilation & $3(9.1 \%)$ & $2(20.0 \%)$ & 0.31 \\
\hline
\end{tabular}


Computed tomography imaging (preferably with oral contrast) should be undertaken when the index of clinical suspicion is high, because it allows the site of mediastinal or intra-abdominal collections to be identified and rules out other pathologies. Of note, OGD performed by an experienced endoscopist using minimal insufflation is an effective means of detecting the site and size of perforation, and is reported to have a sensitivity and specificity of $100 \%$ and $83 \%$ for intrathoracic perforation, respectively. ${ }^{17}$ A positive OGD therefore has a substantial influence on clinical decision making.

Spontaneous perforation was the most common aetiology in our cohort; around one third was associated with underlying cancer of the oesophagus. Squamous cell carcinoma remains the most common malignant cell type globally, despite the rising incidence of adenocarcinoma in the western population. Patients often present at an advanced stage. Of those patients with malignant perforations, all but one had a squamous cell carcinoma of the intrathoracic oesophagus. Perforation either occurs spontaneously or results from concurrent chemoradiotherapy. Ohtsu et $\mathrm{al}^{18}$ reported a perforation rate of $13.9 \%$ (five out of 36 patients) in cases of T4-stage cancer of the oesophagus with concurrent chemoradiotherapy. In our cohort, perforation occurred shortly after completion of radiotherapy in one patient.

The prognosis for patients with perforated oesophageal cancer is poor. The disease is often inoperable and in these circumstances treatment is palliative. ${ }^{19,20}$ Non-operative treatment, such as insertion of a metallic covered stent, is the usual practice at our centre. Stenting of the intrathoracic portion of the oesophagus is technically straightforward and is successful in most cases. Sealing of the perforation site can be confirmed by a subsequent contrast study, and oral intake can be resumed in the absence of a leak. Nevertheless, the prognosis of this group of patients is poor despite the successful placement of a stent, and the hospital mortality rate remains high. Patients most often succumb as a consequence of sepsis caused by the perforation.

Many treatment options are available for nonmalignant perforation, and the treatment strategy should be tailored to the individual. Factors to be considered include the site of perforation, extent of contamination, pre-existing oesophageal disease, and patient co-morbidities. Operative treatment is favoured for perforation of the intra-abdominal oesophagus or perforation that involves the oesophagogastric junction (OGJ). These patients often present with abdominal pain and peritonitis. Laparotomy, primary repair of the perforation, and fashioning of a feeding jejunostomy allow alimentation in the event of persistent leak. The placement of an oesophageal stent that crosses the OGJ has a higher chance of migration and is not recommended.

The intrathoracic oesophagus is the most common site of perforation. Of the three most common causes (Boerhaave's syndrome, iatrogenic perforation, and foreign body ingestion), Boerhaave's syndrome is the most challenging. Traditionally, Boerhaave's syndrome is associated with a mortality rate of up to $30 \% .{ }^{11}$ Patients may present late, the site of perforation is usually at the distal thoracic oesophagus, and there may be extensive contamination due to the high pressure generated by vomiting. Contamination with food particles is common. Operative treatment with primary closure of the perforation and drainage is favoured by many ${ }^{7-9}$; this is also our preferred approach. Many surgeons advocate primary repair irrespective of the timing of presentation. ${ }^{9111,21,22}$ Leak rates after primary repair range from $17 \%$ to $32 \% .^{9,11,21-24}$ Minor leaks can be managed conservatively with drainage, while further surgery (usually exclusion) is required for larger leaks and in the presence of sepsis. Lin et $\mathrm{al}^{23}$ reported that the incidence of postoperative leak was $37.5 \%$ in patients in whom treatment was delayed for more than 48 hours, compared with $0 \%$ in those who were treated more promptly. Wright et $\mathrm{al}^{22}$ reported that three out of the four leaks in their patient cohort were repaired more than 24 hours after perforation. The incidence of leak after primary repair was $25.0 \%$ in our study, which is comparable to other reports in the literature. Of the four leaks, two patients required reoperation and ultimately oesophagectomy; both had presented more than 24 hours after symptom onset.

Endoscopic stenting for benign perforation has been reported in several small case series. Freeman et $\mathrm{al}^{13,14}$ have reported the outcomes of stent placement in patients with iatrogenic and spontaneous perforation. They proposed a hybrid approach, namely a combination of endoscopic and minimally invasive surgical techniques to drain intrathoracic and/or intra-abdominal collections. The main advantage of this strategy is the avoidance of thoracotomy and/or laparotomy. The incidence of stent migration was reported to be approximately $20 \%$ in their cohort of patients with spontaneous oesophageal perforation. ${ }^{14}$ Relative contraindications to stent insertion include a perforation that crosses the OGJ and circumferential necrosis of the oesophagus. In our experience, operative treatment is recommended for the treatment of Boerhaave's syndrome unless the patient is unfit for surgery or declines surgical treatment. Five patients in our series initially treated with stenting subsequently required surgery, of whom four had benign perforations (two with Boerhaave's syndrome and two with iatrogenic perforations). One patient in 
our cohort with oesophageal dissection complicated by perforation underwent stenting in another hospital before transferring to our centre; this patient developed a persistent leak after stenting. In that case, the placement of the stent appeared to have aggravated the leak, and oesophagectomy was eventually required. ${ }^{25}$ In our opinion, stent placement in benign perforation is only suitable for selected patients who present early and have minimal contamination. However, stenting may allow more time for optimisation of a patient's condition if they are initially judged not to be fit for surgery.

Oesophagectomy as a treatment for perforations was first reported in the 1950s. ${ }^{26}$ Singlestage oesophageal resection and reconstruction was first reported by Hendren and Henderson in 1968. ${ }^{27}$ Altorjay et $\mathrm{al}^{28}$ reported a hospital mortality rate of $3.7 \%$ in a series of patients undergoing oesophagectomy for intrathoracic perforation; in this series iatrogenic perforation represented 55.6\% of all perforations. Some surgeons have opined that oesophagectomy may be superior to primary repair in the presence of pre-existing oesophageal disease and of extensive perforation with substantial sepsis, while the general condition of the patient should always be taken into account. ${ }^{28,29}$ There is no consensus about the optimum surgical approach and timing of reconstruction after oesophagectomy. We advocate primary repair as the initial treatment irrespective of the timing of presentation, and oesophagectomy is considered a salvage treatment. In our experience, patients with persistent leak after primary repair and sepsis should undergo oesophageal exclusion to control sepsis before oesophagectomy is contemplated. Oesophagectomy with primary reconstruction can be performed safely after patient optimisation. Oesophagectomy was undertaken in six patients in our cohort; three of these patients had pre-existing oesophageal disease. All patients had a cervical oesophagogastric anastomosis fashioned via the retrosternal route. A cervical anastomosis distant from the infected mediastinum appears to be a safe option..$^{29}$ Thoracotomy is the most common surgical approach, but Yeo et $\mathrm{al}^{30}$ reported using transhiatal oesophagectomy to treat perforated oesophageal cancer in four patients. Thoracotomy is avoided in the transhiatal approach, but this technique can only be considered in perforations of the distal oesophagus and in the presence of minimal mediastinal contamination.

Oesophageal perforation after foreign body ingestion in adults is more common in China as a result of its dietary culture. The foreign body is usually a fish, chicken, or pork bone. An impacted foreign body can usually be retrieved endoscopically; however, oesophageal perforation can occur if there is deep penetration of the foreign body or extensive manipulation during retrieval. The site of perforation is usually the cervical oesophagus, followed by the intrathoracic oesophagus. In severe cases, operative management is indicated; the approach is dependent on the site of perforation, and the site and size of any collection. The aim of management is to drain any collection, remove any residual foreign body, repair the perforated site, and protect the airway. In the absence of sepsis and imaging appearances of a peri-oesophageal collection, conservative treatment may be warranted. Operative drainage may be necessary if there is a sizeable collection and if there is sepsis. Mediastinitis and sepsis are more likely after intrathoracic perforation, and would dictate treatment strategy.

It is essential to identify factors associated with mortality after oesophageal perforation so as to improve treatment and outcomes. Early diagnosis and management (in the golden 24 hours') are reportedly associated with superior outcomes. $^{1,6}$ Malignant perforation, sepsis, the need for mechanical ventilation on presentation, and pulmonary co-morbidity are reported to have a significant impact on overall survival..$^{5}$ In our cohort, pulmonary co-morbidity, hepatic disease, and malignant perforation were associated with risk of death. A recent meta-analysis of 75 studies that included 2971 patients reported a pooled mortality rate of $11.9 \%$ (95\% confidence interval, 9.7\%-14.3\%). ${ }^{3}$ Of the different aetiologies, spontaneous perforation had the highest mortality rate of $14.8 \%{ }^{3}$

Oesophageal perforation remains a difficult condition to treat despite advances in surgery, endoscopic treatment, and ICU care. The mortality rate is still substantial with modern therapies. The presence of pre-existing pulmonary disease, hepatic disease, and perforation associated with malignancy was significantly associated with hospital mortality in our cohort. Oesophagectomy for salvage had a reasonable success rate in selected patients.

\section{Declaration}

All authors have disclosed no conflicts of interest.

\section{References}

1. Vallböhmer D, Hölscher AH, Hölscher M, et al. Options in the management of esophageal perforation: analysis over a 12-year period. Dis Esophagus 2010;23:185-90.

2. Søreide JA, Konradsson A, Sandvik OM, Øvrebø K, Viste A. Esophageal perforation: clinical patterns and outcomes from a patient cohort of Western Norway. Dig Surg 2012;29:494-502.

3. Biancari F, D'Andrea V, Paone R, et al. Current treatment and outcome of esophageal perforations in adults: systematic review and meta-analysis of 75 studies. World J Surg 2013;37:1051-9.

4. Abbas G, Schuchert MJ, Pettiford BL, et al. Contemporaneous management of esophageal perforation. Surgery 2009;146:749-55.

5. Bhatia P, Fortin D, Inculet RI, Malthaner RA. Current 
concepts in the management of esophageal perforations: a twenty-seven year Canadian experience. Ann Thorac Surg 2011;92:209-15.

6. Shaker H, Elsayed H, Whittle I, Hussein S, Shackcloth M. The influence of the 'golden 24-h rule' on the prognosis of oesophageal perforation in the modern era. Eur I Cardiothorac Surg 2010;38:216-22.

7. Brinster CJ, Singhal S, Lee L, Marshall MB, Kaiser LR, Kucharczuk JC. Evolving options in the management of esophageal perforation. Ann Thorac Surg 2004;77:1475-83.

8. Eroglu A, Can Kürkcüogu I, Karaoganogu N, Tekinbaş C, Yimaz O, Başog M. Esophageal perforation: the importance of early diagnosis and primary repair. Dis Esophagus 2004;17:91-4.

9. Jougon J, Mc Bride T, Delcambre F, Minniti A, Velly JF. Primary esophageal repair for Boerhaave's syndrome whatever the free interval between perforation and treatment. Eur J Cardiothorac Surg 2004;25:475-9.

10. Flynn AE, Verrier ED, Way LW, Thomas AN, Pellegrini CA Esophageal perforation. Arch Surg 1989;124:1211-4.

11. Lawrence DR, Ohri SK, Moxon RE, Townsend ER, Fountain SW. Primary esophageal repair for Boerhaave's syndrome. Ann Thorac Surg 1999;67:818-20.

12. Fischer A, Thomusch O, Benz S, von Dobschuetz E, Baier P, Hopt UT. Nonoperative treatment of 15 benign esophageal perforations with self-expandable covered metal stents. Ann Thorac Surg 2006;81:467-72.

13. Freeman RK, Van Woerkom JM, Ascioti AJ. Esophageal stent placement for the treatment of iatrogenic intrathoracic esophageal perforation. Ann Thorac Surg 2007;83:2003-7.

14. Freeman RK, Van Woerkom JM, Vyverberg A, Ascioti AJ. Esophageal stent placement for the treatment of spontaneous esophageal perforations. Ann Thorac Surg 2009;88:194-8.

15. Kiernan PD, Khandhar SJ, Fortes DL, Sheridan MJ, Hetrick V. Thoracic esophageal perforations. Am Surg 2010;76:1355-62.

16. Dasari BV, Neely D, Kennedy A, et al. The role of esophageal stents in the management of esophageal anastomotic leaks and benign esophageal perforations. Ann Surg 2014;259:852-60.

17. Horwitz B, Krevsky B, Buckman RF Jr, Fisher RS, Dabezies MA. Endoscopic evaluation of penetrating esophageal injuries. Am J Gastroenterol 1993;88:1249-53.

18. Ohtsu A, Boku N, Muro K, et al. Definitive chemoradiotherapy for $\mathrm{T} 4$ and/or M1 lymph node squamous cell carcinoma of the esophagus. J Clin Oncol 1999;17:2915-21.

19. Di Franco F, Lam PJ, Karat D, Hayes N, Griffin SM. Iatrogenic perforation of localized oesophageal cancer. Br J Surg 2008;95:837-9.

20. Jethwa P, Lala A, Powell J, McConkey CC, Gillison EW, Spychal RT. A regional audit of iatrogenic perforation of tumours of the oesophagus and cardia. Aliment Pharmacol Ther 2005;21:479-84.

21. Whyte RI, Iannettoni MD, Orringer MB. Intrathoracic esophageal perforation. The merit of primary repair. J Thorac Cardiovasc Surg 1995;109:140-4.

22. Wright CD, Mathisen DJ, Wain JC, Moncure AC, Hilgenberg AD, Grillo HC. Reinforced primary repair of thoracic esophageal perforation. Ann Thorac Surg 1995;60:245-8.

23. Lin Y, Jiang G, Liu L, et al. Management of thoracic esophageal perforation. World J Surg 2014;38:1093-9.

24. Richardson JD. Management of esophageal perforations: the value of aggressive surgical treatment. Am J Surg 2005;190:161-5.

25. Zhu RY, Law TT, Tong D, Tam G, Law S. Spontaneous circumferential intramural esophageal dissection complicated with esophageal perforation and esophagealpleural fistula: a case report and literature review. Dis Esophagus 2016;29:872-9.

26. Johnson J, Schwegman CW, MacVaugh H III. Early esophagogastrectomy in the treatment of iatrogenic perforation of the distal esophagostomy. J Thorac Cardiovasc Surg 1956;32:827-31.

27. Hendren WH, Henderson BM. Immediate esophagectomy for instrumental perforation of the thoracic esophagus. Ann Surg 1968;168:997-1003.

28. Altorjay A, Kiss J, Vörös A, Szirányi E. The role of esophagectomy in the management of esophageal perforation. Ann Thorac Surg 1998;65:1433-6.

29. Orringer MB, Stirling MC. Esophagectomy for esophageal disruption. Ann Thorac Surg 1990;49:35-42.

30. Yeo CJ, Killemoe KD, Klein AS, Zinner MJ. Treatment of instrumental perforation of esophageal malignancy by transhiatal esophagectomy. Arch Surg 1988;123:1016-8. 